\title{
Interval type-2 fuzzy logic PID excitation control system with AVR in power system stability analysis
}

\author{
Manoj Kumar Sharma ${ }^{1 *}$, R.P. Pathak ${ }^{2}$, Manoj Kumar Jha ${ }^{3}$, M.F. Qureshi ${ }^{4}$ \\ ${ }^{1}$ NIT Raipur, Chattisgarh, India \\ ${ }^{2}$ Mathematics Dept, NIT Raipur, Chattisgarh, India \\ ${ }^{3}$ Naveen K.T.C. College Salni, Janjgir-Champa, Chattisgarh, India \\ ${ }^{4}$ Department of electrical Engg., DTE, Raipur, Chattisgarh, India
}

https://doi.org/10.18280/ama_c.730411

Received: 26 June 2018

Accepted: 15 October 2018

\section{Keywords:}

interval Type-2 fuzzy logic controller (IT2FLC), PID controller, control systems, controlled AVR

\begin{abstract}
The application of a simple microcontroller to deal with a three variable input and a single output interval Type-2 fuzzy logic controller (IT2FLC), with Proportional Integral Derivative (PID) response control built-in has been tested for an automatic voltage regulator (AVR). The interval Type-2 fuzzifiers are based on fixed range of the variables of output voltage. The control output is used to control the wiper motor of the auto transformer to adjust the voltage, using interval Type-2 fuzzy logic principles, so that the voltage is stabilized. In this report, the author will demonstrate how interval Type-2 fuzzy logic might provide elegant and efficient solutions in the design of multivariable control based on experimental results rather than on mathematical models. This works aims to develop a controller based on PID and Interval Type-2 Fuzzy Logic Controller (IT2FLC) to simulate an automatic voltage regulator (AVR) in transient stability power system analysis. It was simulated a one machine control to check if the Interval Type-2 Fuzzy Logic Controller (IT2FLC) and PID controller implementation was possible. After that the developed controller was applied in field excitation system to show its behavior, which results were compared to the results obtained with the AVR itself.
\end{abstract}

\section{INTRODUCTION}

In lieu of the advances in power electronics and microprocessors, digitally controlled induction motor drives have become increasingly popular. In many industrial drives advanced digital control strategies for the control of field oriented induction motor drives with a conventional speed PID controller have gained the widest acceptance in high performance AC servo systems, if the load changes are small and the operating conditions do not force the system too far away from the linear equilibrium point. However, in certain applications, such as steel mills, paper mills, robotics, machine tools, the drive operates under a wide range of load change characteristics and the system parameters vary substantially. To overcome this drawback, the control algorithm should include a complicated computation process to eliminate the variations in the load disturbance and systems parameters and also obtain high performance AC system. However, the control algorithms applicable to these systems have become increasingly more complicated, requiring extensive computations for real-time implementation. In recent years, Artificial Neural Network intelligent (ANN) and Fuzzy Logic Controllers (FLC) have gained great important and proved their dexterity of many respects. On the other hand, FLC has been implemented on many platforms such as digital signal processor (DSP), PC or off the self microcontroller. These platforms have many advantage and disadvantages. The FLC developed on DSP or PC can quickly process fuzzy computation to generate control efforts, but the physical size of the system may too big and quite expensive for a small DC motor application. Fuzzy logic does not replace conventional control techniques, but provides a solution where conventional methods are not satisfactory. When a present control solution actually exists, replacement of a fuzzy logic may not be necessary. But this is not often true. An alternative solution by Fuzzy logic may be better. It all depends on how the system under control is known to us in its parameters, variables and relationships of control. If determined values of such variables are not existing, then fuzzy logic based classification of the variables provides a solution which may be better than a method of control using assumed relationship. In this paper, fuzzy logic PID control of Automatic Voltage Regulator is constructed with fuzzy logic and its performances are evaluated. At the view of power system, the excitation system must contribute for the voltage control and enhancement of system stability. It must be able to respond quickly at any occurrence of disturbances enhancing the transient stability and the small signal stability. In the excitation control system the synchronous generator consists of boiler, governor, and exciter controls. In present days the exciter is a dc generator driven by either steam turbine or an induction motor. The voltage regulator in an excitation system controls the output of the exciter so that the generated voltage and reactive power change in the desired way. Automatic voltage regulator (AVR) is a controller that senses the generator output voltage and then initiates corrective action by changing the exciter control in the desired direction. AVR is of great interest in studying stability with its speed, because of high inductance in generator field winding, it is difficult to make rapid changes in field current. There will a considerable lag in control function and a major obstacle to overcome in designing a regulating system. The purpose of this work is the development of a PID 
and fuzzy logic controller in order to simulate the automatic voltage regulator behavior.

\section{DYNAMIC POWER SYSTEM MODEL}

In this paper the dynamic model of power system, namely, a single machine connected to an infinite bus system was considered. It consists of a single synchronous generator (turbo-Alternator) connected through a parallel transmission line to a very large network approximated by an infinite bus as shown in fig.1.

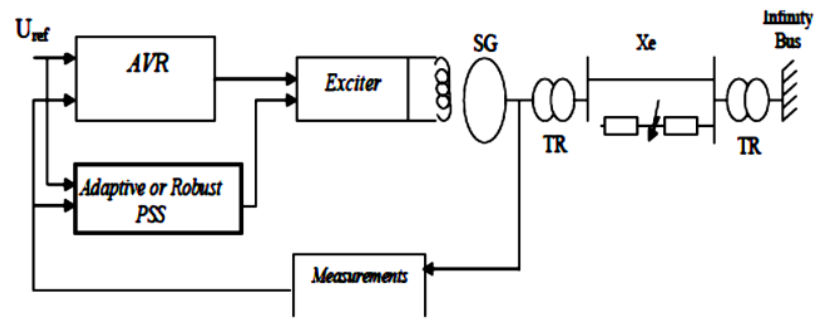

Figure 1. Block schematic diagram of the proposed standard power system

Let the state variable of interest be the machine's rotor speed variation and the power system acceleration

$x_{1}=\Delta \omega$

$x_{2}=\Delta P=P_{m}-P_{e}$

where $x 1$ is the speed deviation and $x 2$ is accelerating power, $P m$ and $P e$ represents respectively the mechanical and electrical power. It is possible to represent the power system in the following form.

$$
\begin{aligned}
& x_{1}=\alpha x_{2} \\
& O \dot{x}_{2}=f\left(x_{1}, x_{2}\right)+g\left(x_{1}, x_{2}\right) u \\
& y=x_{1}
\end{aligned}
$$

where $\alpha=1 / 2 H$ and $H$ is the per unit inertia constant of the machine. $x=\left[\begin{array}{ll}x 1 & x 2\end{array}\right]$ is the state vector of the system and $f$ $\left(x_{1}, x_{2}\right)$ and $g\left(x_{1}, x_{2}\right)$ are nonlinear functions and $u$ is the PSS (Power System Stabilizer) control signal to be designed. We need to express $f$ and $g$ as function of active power $P$ and reactive power $Q$. The governor time constant is large compared to the time constants of synchronous machine and its exciter, the power system can be easily put in transient period after a major disturbance has occurred in the system. On the basis of investigation carried out, the main points of adaptive Neuro Fuzzy and standard fuzzy PSS automated design methods were formulated. The nonlinear model of power system can be represented by the set of different linearized models. For such models, the adaptive simple fuzzy and hybrid ANFIS compensators can be synthesis and calculated by means of MATLAB Software. The family of test regulators is transformed into united fuzzy knowledge base with the help of hybrid learning procedure. In order to solve the main problem of the rule base design, which called "the curse of dimensionality", and decrease the rule base size the scatter partition method was used. In this case, every rule from the knowledge base is associated with some optimal gain set.
The advantage of this method is the practically unlimited expansion of rule base. It can be probably needed for some new operating conditions, which are not provided during learning process.

\section{TRANSIENT STABILITY ANALYSIS}

In an electrical system reliability there is a demand at synchronous generators working in parallel and with adequate capacity to satisfy the load demand. At certain cases the generator looses synchronism with the rest of the system, significant voltage and current fluctuation can occur and transmission lines can be automatically removed from the system configuration another demand is in maintaining power system integrity. The high voltage transmission system connects the generation sources to the load center which requires the power system topology study, where all electrical systems are connected to each other. At normal load condition in power system there is a disturbance in synchronous machine voltage angle rearrangement. At each occurrence of disturbances an unbalance is created between the system generation and load, so a new operation point will be established and consequently there will be voltage angle adjustments. The system adjustment to its new operation condition is called "transient period" and the system behavior during this period is called "dynamic performance". It can be said that the system oscillatory response during the transient period, short after a disturbance is damped and the system goes in a definite time to a new operating condition, so the system is stable. This means that the oscillations are damped, that the system has inherent forces which tend to reduce the oscillations.

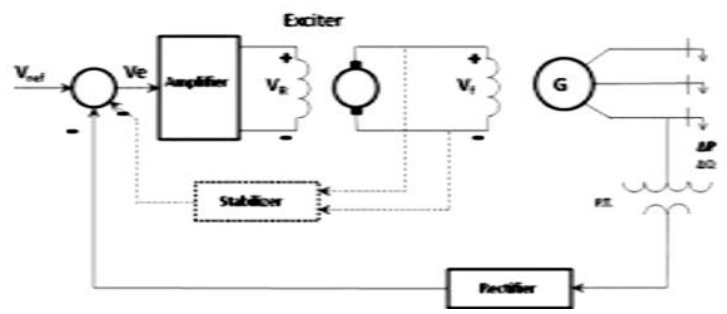

Figure 2. Typical arrangement of simple AVR

In a power system the instability can be shown in different ways, according to its configuration and its mode of operation, but it can also be observed without synchronism loss. Automatic devices control generators in its voltage output and frequency, in order to keep them constant according to preestablished values.

The automatic devices are:

Automatic voltage regulator

Governor

The governor is slower in is action loop than AVR. This is associated mainly to its final action in the turbine. The main objective of the automatic voltage regulator is to control the terminal voltage by adjusting the generators exciter voltage. It must keep track of the generator terminal voltage all time and under any load condition, working in order to keep the voltage within pre-established limits. Based on this it can be said that AVR also controls the reactive power generated and the power factor of the machine once these variables are related to the generator excitation level. 


\section{PID CONTROLLER}

The PID controller is simple and easy to implement. It is widely used in industries to solve various control problems. It is used to improve dynamic response as well as to reduce or eliminate steady state error. The derivative controller adds a finite zero to the open-loop plant transfer function and improves the transient response. The integral controller adds a pole at the origin, thus increasing system type by one and reducing the steady state error due to a step function to zero.

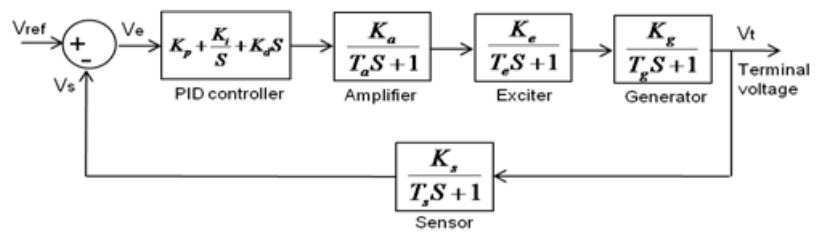

Figure 3. Closed loop block diagram of AVR with PID controller

The PID controller transfer function is,

$\mathrm{E}(\mathrm{s}) / \mathrm{U}(\mathrm{s})=\mathrm{Kp}+\mathrm{Ki} / \mathrm{s}+\mathrm{Kd} . \mathrm{S}$

$\mathrm{Kp}$ is the proportional gain, $\mathrm{Ki}$ is the integration gain, and $\mathrm{Kd}$ is the derivative gain. The proportional part of the PID controller reduces error responses to disturbances. The integral term of the error eliminates the steady state error and the derivative term of the error dampens the dynamic response and thereby improves the stability of the system.

\section{PID controller design for AVR system}

It is an important matter for the stable electric power service to develop automatic voltage regulator (AVR) of the synchronous generator with a high efficiency and fast response. Until now the analog PID controller is generally used for the AVR because of its simplicity and low cost. There are five models as follows:

PID controller model

Amplifier model

Exciter model

Generator model

Sensor model

\section{ARTIFICIAL INTELLIGENCE AND INTERVAL TYPE-2 FUZZY LOGIC CONTROLLER}

Controlling complex systems highly non-linear has shown to be very difficult using conventional control theory. The artificial intelligence with its natural language has proven to be useful in these cases as it deals with uncertainties, what brings it closer to human being logic thought. In artificial intelligence fuzzy logic was the chosen one.

\section{A. Fuzzy logic controller data}

The fuzzy logic use has received a lot of attention in the recent years because of its usefulness in reducing the model's complexity in the problem; it employs linguistic terms that deals with the causal relationship between input and output constraints. This logic was developed based on Lofti Zadeh's 1960s fuzzy set theory, which was motivated mainly by the conviction that the traditional analysis methods were inadequate to describe phenomena whose constraints were not related by differential equations. This theory provides a way of representing the vague notions through the element and its membership in this set.

\section{B. Fuzzy set}

The fuzzy set is a distinct element collection with a relevancy or inclusion variable degree, which characteristic function known as membership function, determines its relevancy degree. The fuzzy set $F$ in a $U$ universe is characterized by a membership function $\mu_{F}$ from $[0,1]$, denoted by:

$$
\mu F-U \rightarrow[0,1]
$$

The fuzzy set can be seen as a generalization of a regular set in which the membership has only two values $\{0,1\}$. A fuzzy set $F$ in $U$ can be represented as an ordinate pair set of a generic element $\mathrm{u}$ and its membership degree $\mu_{F}$.

\section{The fuzzy controller}

Controllers based on the fuzzy logic give the linguistic strategies control conversion from expert knowledge in automatic control strategies. The first fuzzy logic based controllers application was done by Assilian and Mandani. The recent fuzzy logic controller application in water quality control, train operation automatic system, elevators control, nuclear reactor control and fuzzy computers shows an efficient way for using the fuzzy control in complex process which can be controlled by a skilful human being without knowing its dynamic. The fuzzy logic controller consists of a linguistic propositions and rules set, which defines individual control actions.

\section{Fuzzy controller project}

The development of the control system based on fuzzy logic involves the following steps:

. Fuzzification Strategy,

. Data Base Building,

. Rule Base Elaboration,

. Inference Machine Elaboration,

. Defuzzification Strategy.

Fig.4 shows a fuzzy logic system controller configuration that emphasizes its main components. The input constraints were terminal voltage error and its variation; the output constraint was the increment of the voltage exciter. A triangular membership function was used which could be compressed or expanded, but not when rule re-insertion was used.

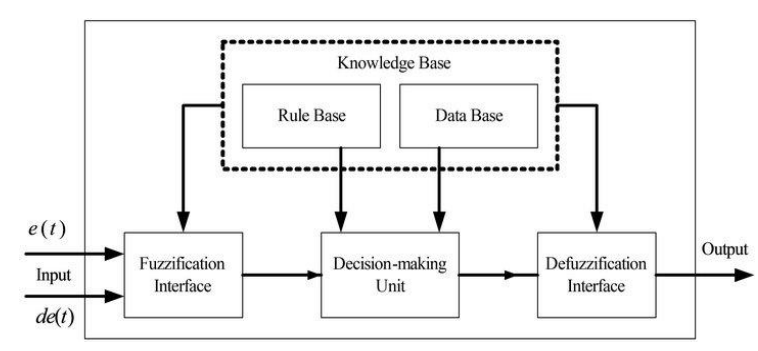

Figure 4. Fuzzy controller basic configuration

\section{Software implementation (interval type-2 fuzzy logic)}

In this research, fuzzy logic is used to control the DC motor. The DC motor controls the position of the wiper which slides on an auto-transformer. With fuzzy logic, output voltage is stabilized while variation of the input range is $150 \mathrm{~V}$ to $250 \mathrm{~V}$. 


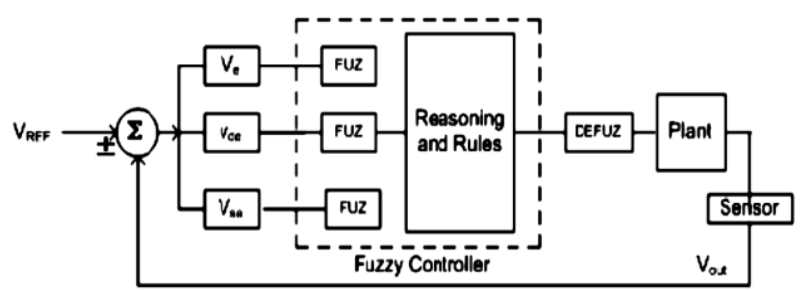

Figure 5. The fuzzy logic PID controller used for AV regulator

A. Fuzzy logic implementation on embedded microcomputers

Fuzzy logic operators provide formal method of manipulating linguistics variable. Linguistic variables are nonprecise variables that often convey a surprising amount of information.

The linguistics variables so common in everyday speech convey information about an object under observation. Linguistic variables in a computer require a formal way of describing a linguistics variable in crisp terms the computer can deal with. Fig. 6 shows the relations between measured error voltage and the linguistic term large negative and large positive.

The following figure show the relationship of other linguistics variables used in fuzzy logic controlled voltage regulator.

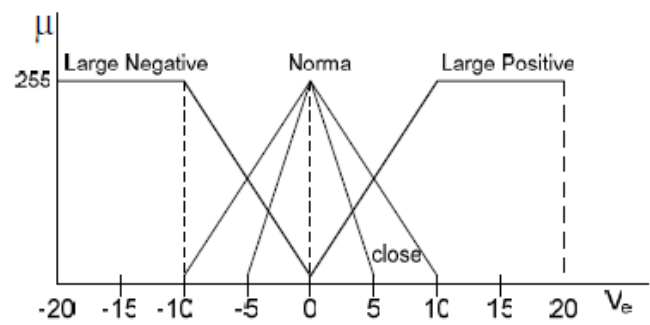

Figure 6. The relationship between linguistics variable and error voltage

\section{Fuzzy rules}

Instead of using mathematical formula a Fuzzy Logic control uses fuzzy rules to make a decision and generate the control effort. The rules are in the form of IF-THEN statements. For example, If the error voltage (Ve) is equal to Large Positive THEN change in the armature voltage is Large Negative. The matters in defining rules are how many rules should be used and how to determine the relation in IF-THEN statements. Actually, the solutions are based on the experience of a designer or the previous knowledge of the system. The critical point is if there is not sufficient knowledge applied in the design, the result could be drastically bad. In this paper, the following IF-THEN rules are used to control the armature voltage of the motor.

1 If error voltage (Ve) is Large Negative then the armature voltage is Large Positive (LP).

2 If error voltage $(\mathrm{Ve})$ is Large Positive then the armature voltage is Large Negative (LN).

3 If error voltage (Ve) is normal and change of error voltage (Vde) is Positive then the armature voltage (Vout) is Small Negative (SN).

4 If error voltage (Ve) is normal and change of error voltage (Vde) is Negative then the armature voltage (Vout) is Small Positive (SP).
5 If error voltage (Ve) is close and sum of error voltage (Vse) is Large Positive then the armature voltage (Vout) is Small Negative (SN).

6 If error voltage $(\mathrm{Ve})$ is close and sum of error voltage (Vse) is Large Negative then the armature voltage (Vout) is Small Positive (SP)

\section{Centroid calculation defuzzification method}

The result of the defuzzification has to be a numeric value which determines the duty factor of the PWM signal used to drive the motor. It is obtained by finding the centroid point of the function which is the result of the multiplication of the output membership and output vector Y. The general mathematical formula which is used to obtain the centroid point is

$$
\text { Output }=\frac{\sum_{\mathrm{i}=1}^{4} \mathrm{Y}[\mathrm{i}] \times \text { multifact }[\mathrm{i}]}{\sum_{\mathrm{i}=1}^{4} \mathrm{Y}[\mathrm{i}]}
$$

$\mathrm{Y}[\mathrm{i}]$ is the $\mathrm{i}^{\text {th }}$ members of the output vector multifact [i] are the multiplying coefficients of the output membership function.

Fig.7 shows a graphical representation of the output membership used in this application with the coefficients [$256-126128255]$.

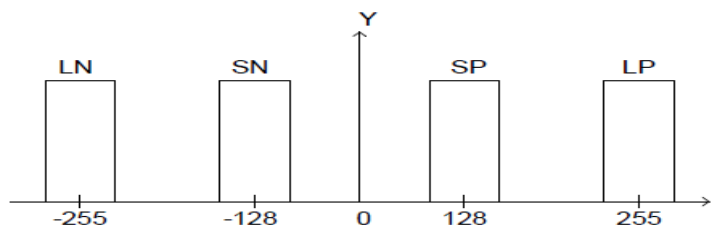

Figure 7. Output membership function

\section{Fuzzy controller project}

In the development of the control system based on fuzzy logic involves the following steps:

Fuzzification Strategy

Data Base Building

Rule Base Elaboration

Interference Machine Elaboration

Defuzzification Strategy.

\section{SIMULATION RESULTS AND DISCUSSION}

In the system study standard IEEE type 'SMIB', based on "Synchronous generator-transmission line-infinite bus" the main attention was devoted to receive a hybrid learning adaptive Neuro-Fuzzy Power System Stabilizer 'NFCPSS' (based on Hybrid technology ANFIS) and simple Fuzzy PSS 'SFCPSS' and a conventional Russian PSS with a Strong Action 'RSAPSS' (appendix 1), working in the wide spectrum of operating conditions. The change of operating conditions corresponds to the variation of transmission line parameters $(X e)$ and the powers of Turbo-Alternators $P G$ and $Q G$. Certain attention was devoted to the problem of the reactive power consumption (under-excitation modes), which is very important for all electric power systems.

The illustrations with using the proposed Adaptive Nonlinear Neuro - fuzzy PSS, standard Fuzzy and the test conventional PID control techniques opportunities for large scale of TA: TBB-200, TBB-500, BBC-720 and TBB-1000 (their parameters in Appendix 2), are given in Table I on the 
basis of comparison of the damping coefficient $\alpha$ (study of static stability). The results shown that, the Adaptive Neuro Fuzzy regulator allows receiving an improving performances quality in comparison with the application of standard fuzzy and conventional compensators, without resetting optimal gains of the NFCPSS under different conditions of used Turbo Alternators and transmission line parameters $(\mathrm{Xe})$. The electromechanical damping oscillations of the SG parameters under different operating modes in controllable power system, equipped by hybrid learning 'NFCPSS' (Blue), standard fuzzy 'SFCPSS' (Red) and conventional PID 'RSAPSS' (green) controllers are given in Fig. 8: (a) interior angle $\delta$, and (b) Stator terminal voltage of TA. Results of time domain simulations of the turbo.

Alternator series TBB - 500, confirm both a high effectiveness of the test simple fuzzy Regulator, which has various adjustments of regulation channels in different operating conditions in comparison with using the conventional PID Russian PSS, but more large degree of performances and much more robustness of the dynamic of power system are improving and obtained by using the non linear learning Neuro - fuzzy PSS 'NFCPSS' (fig. 8 (a) and (b) for examples), these due to the initial nonlinear (real) characteristics of the power system study and the necessity of high adaptability of PSS. After appearance of the real (nonlinear) properties of the SMIB power system, and especially in the under - excitation (mode 2) of the electric station, the traditional RSAPSS and the simple fuzzy SFCPSS controllers quickly loses there effectiveness under condition of uncertainties, in the same time where the hybrid learning NFCPSS stabilizer improve its efficiency by improving dynamics performances and more robustness.

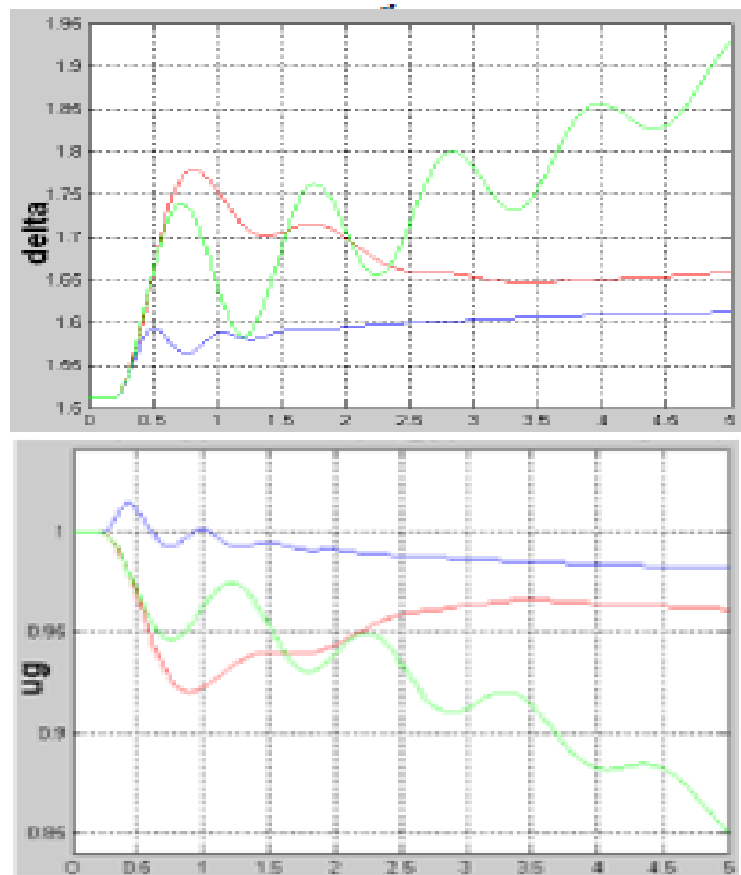

1. Nominal mode for TBB-500: $\mathrm{Xe}=0.5, \mathrm{Pg}=0.85, \mathrm{Qg}=0.25$ (p.u)

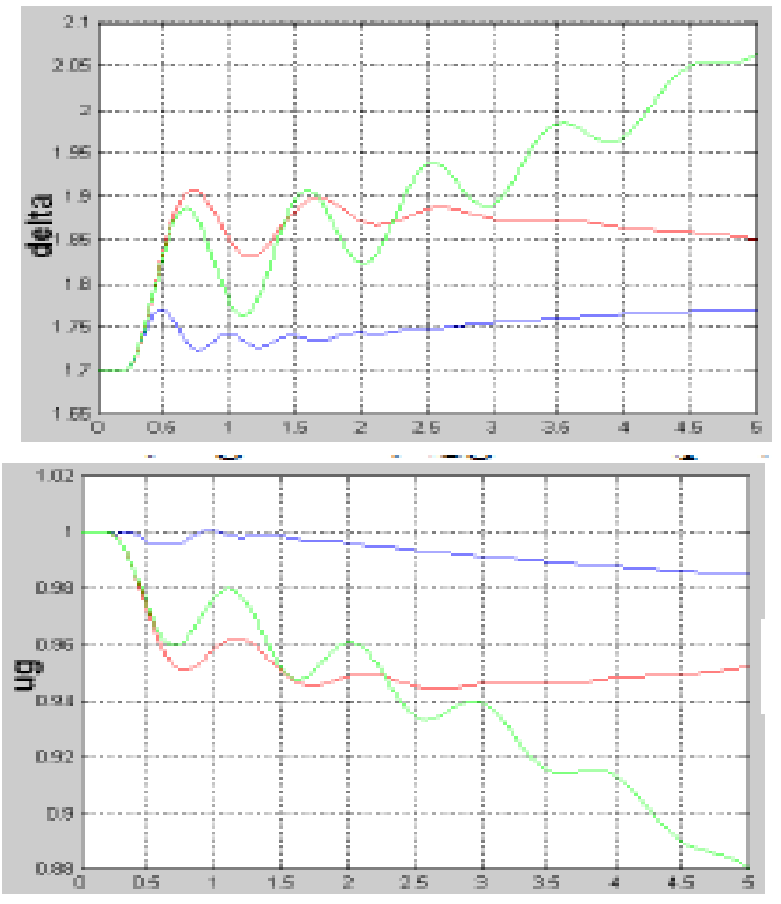

2. Under-excited mode TBB-500: $\mathrm{Xe}=0.5, \mathrm{Pg}=0.85, \mathrm{Qg}=-0.2$ (p.u)

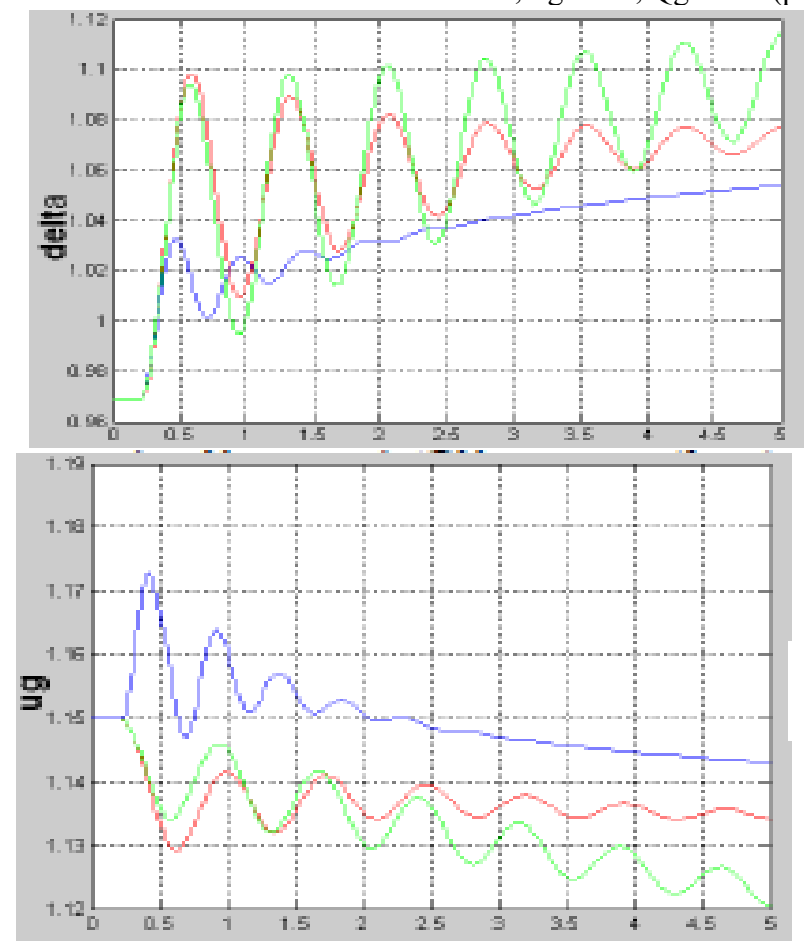

3. Over-excited mode TBB-500: $\mathrm{Xe}=0.5, \mathrm{Pg}=0.85, \mathrm{Qg}=0.65$ (p.u)

Figure 8. Electromechanical damping oscillations of TA (TBB-500) parameters, under different modes with hybrid learning NFCPSS (Blue), standard fuzzy SFCPSS (Red) and Conventional RSAPSS (green) stabilizers: $(a 1,2,3)$ interior angle $\delta,(b 1,2,3)$ Stator terminal voltage of SG 
Table 1. Parameters of the used Turbo -Alternators

\begin{tabular}{|c|c|c|c|c|c|}
\hline Paramerers & TBB-200 & TBB-500 & $B B C-720$ & TBB-1000 & unit \\
\hline $\begin{array}{l}\text { Nominal } \\
\text { power }\end{array}$ & 200 & 500 & 720 & 1000 & $M W$ \\
\hline $\begin{array}{l}\text { Power } \\
\text { factor }\end{array}$ & 0.85 & 0.85 & 0.85 & 0.9 & p.u. \\
\hline$x_{d}$ & 2.56 & 1.869 & 2.67 & 2.35 & p.u. \\
\hline$x_{4}$ & 2.56 & 1.5 & 2.535 & 2.24 & p.u. \\
\hline$x$ & 0.222 & 0.194 & 0.22 & 0.32 & p.u. \\
\hline$x_{y}$ & 2.458 & 1.79 & 2.587 & 2.173 & p.u. \\
\hline$x_{8}$ & 0.12 & .115 & 0.137 & 0.143 & p.u. \\
\hline $\boldsymbol{Y}_{s, 6}$ & 0.0996 & 0.063 & 0.1114 & $0.1+8$ & p.u. \\
\hline 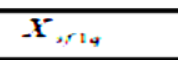 & 0.131 & 0.0407 & 0.944 & 0.263 & p.u. \\
\hline$X_{s, 24}$ & 0.9415 & 0.0407 & 0.104 & 0.104 & p.u. \\
\hline$R_{\alpha}$ & 0.0055 & 0.0055 & 0.0055 & 0.005 & p.u. \\
\hline$R_{r}$ & 0.000844 & 0.000844 & 0.00176 & 0.00132 & p.u. \\
\hline$R_{12}$ & 0.0481 & 0.0481 & 0.003688 & 0.002 & p.u. \\
\hline $\boldsymbol{R}_{10}$ & 0.061 & 0.061 & 0.00277 & 0.023 & p.u. \\
\hline$R_{i_{4}}$ & 0.115 & 0.115 & 0.00277 & 0.023 & p.u. \\
\hline
\end{tabular}

Table 2. The output rule base used by fuzzy logic controller

\begin{tabular}{cccccc}
\hline \multicolumn{5}{c}{ ERROR VARIATION } \\
\hline ERROR & MN & MN & SN & SN & Z \\
& MN & SN & SN & Z & SP \\
& SN & SN & Z & SP & SP \\
SN & Z & SP & SP & MP \\
Z & SP & SP & MP & MP \\
SP & SP & MP & MP & LP \\
SP & MP & MP & LP & LP \\
\hline
\end{tabular}

\section{NUMERICAL SIMULATION}

We use the same system as Fig.9 for numerical simulation. The simulation data are shown in Appendix A in details. For comparison, a conventional generator-transformer unit
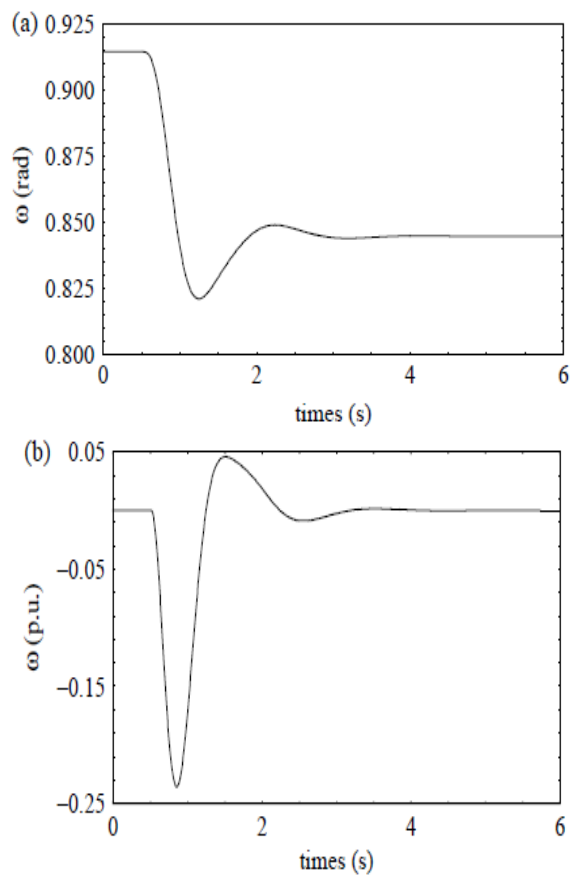

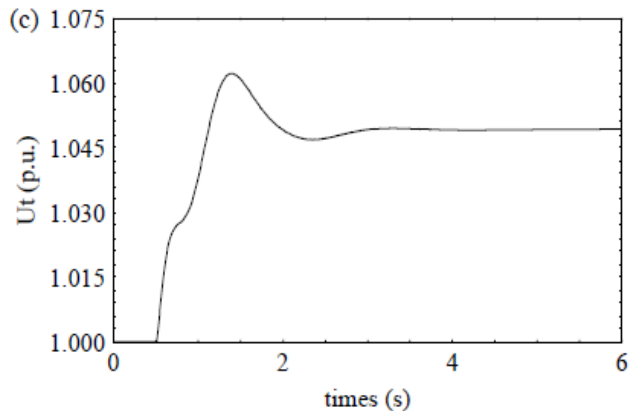

Figure 9. Response to 5\% voltage step increase for the conventional generator-transformer unit: (a) power angle, (b) speed, and (c) voltage at the generator terminals. equipped with AVRCPSS controller is also simulated

The control of PET is very flexible, e.g. it can make the generator always operate under unit power factor. Hence, we use different initial operation points for the two systems in the simulation. The initial operation point for the generator-PET unit is P1Z1.0, Q1Z0.0, P2Z1.0, and Q2Z0.484. On the other hand, the operation point for the conventional generatortransformer unit is P1Z0.8, Q1Z0.443. Three different disturbances are examined in the simulations.

\section{$7.15 \%$ voltage step increase}

The system responses of 5\% voltage step increase in the generator terminal are considered for the conventional generator-transformer unit, while the system responses of 5\% voltage step increase in PET high voltage bus are studied for the generator-PET unit. Simulation results are shown in Figs.10 and 11. Compared with the conventional generatortransformer unit with the AVRCPSS controller, it can clearly be observed that the oscillation magnitude of the generator is very small for the coordinated controller, and the voltage reaches its steady value in a short period. 

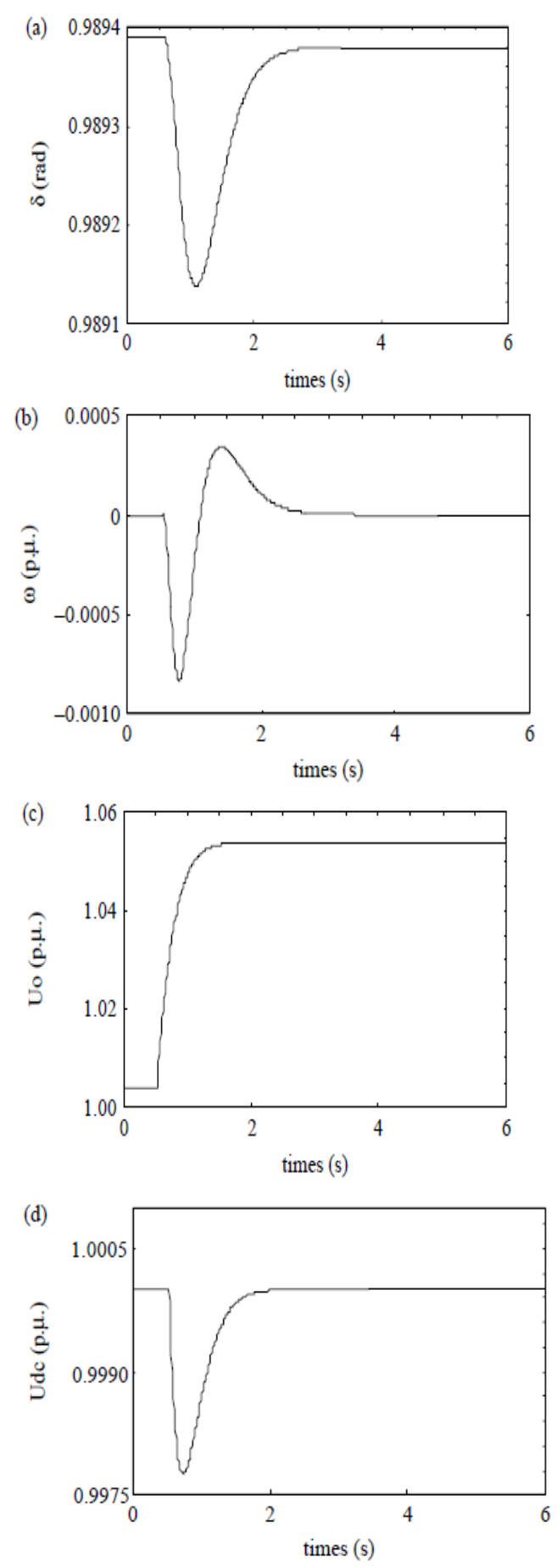

Figure 10. Response to 5\% voltage step increase for the generator-PET unit: (a) power angle, (b) speed, (c) voltage at the high voltage bus of PET, and (d) DC link voltage of PET

\subsection{Three-phase to ground fault}

A three-phase to ground fault is applied at the high voltage bus, and cleared after $100 \mathrm{~ms}$. The responses are shown in Figs. 11 and 12. Clearly the optimal coordinated controller can damp the oscillation much faster than the conventional approach, and improve terminal voltage performance as well.

\subsection{Opening and closing of one of the double-circuit transmission lines}

One of the double-circuit transmission lines is opened suddenly and then closed. The responses are shown in Figs. 9 and 10, which confirm the effectiveness of the proposed control strategy.
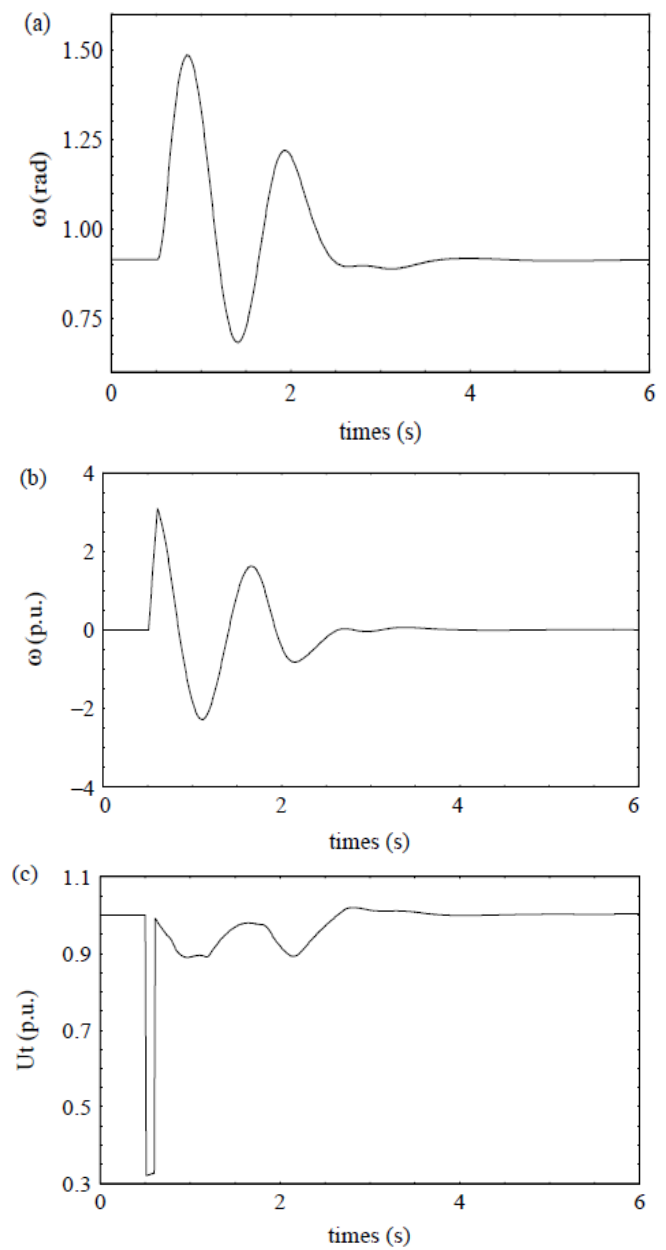

Figure 11. Response to three-phase to ground fault for the conventional generator-transformer unit: (a) power angle, (b) speed, and (c) voltage at the generator terminals
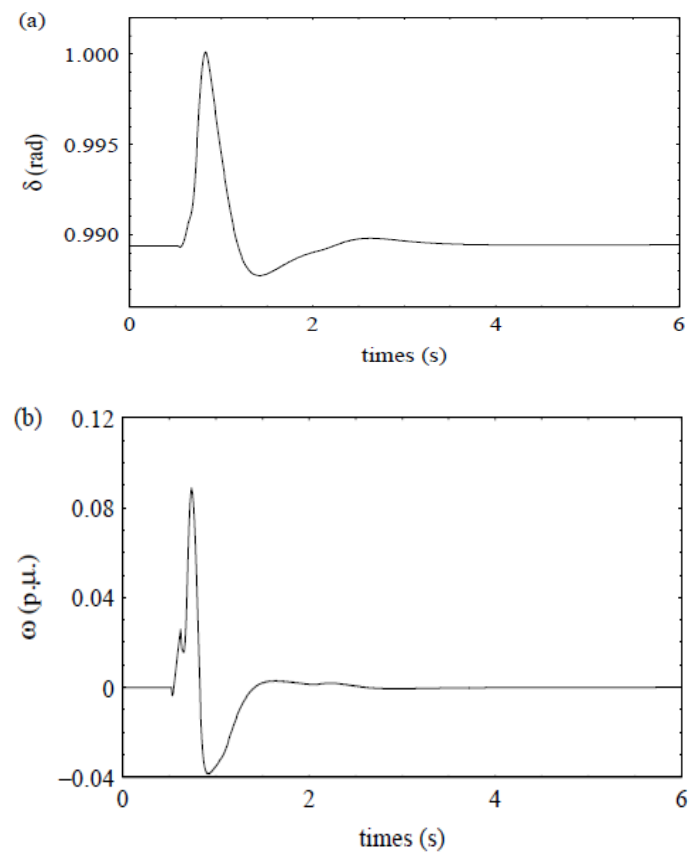

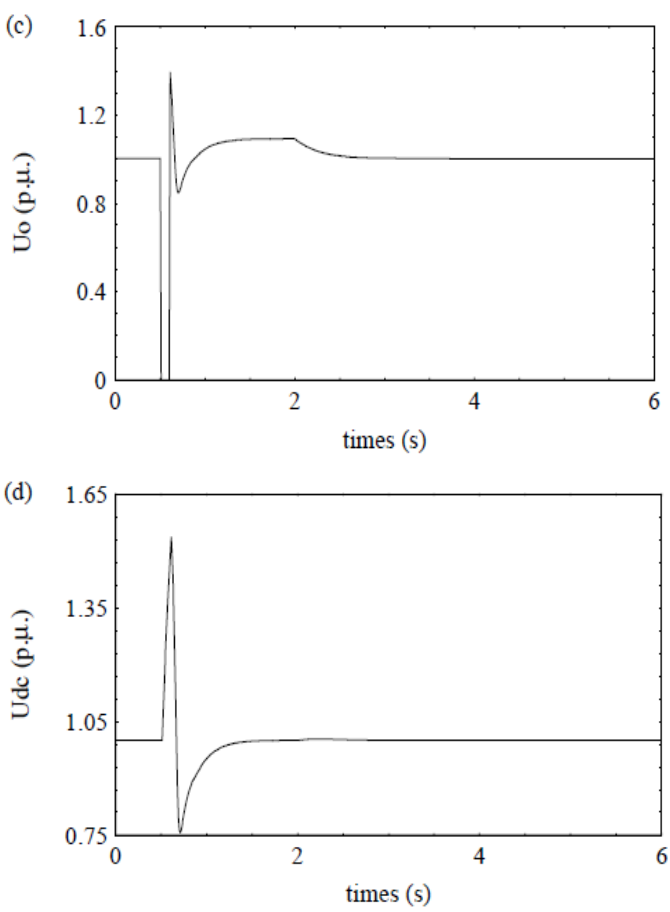

Figure 12. Response to three-phase to ground fault for the generator-PET unit: (a) power angle, (b) speed, (c) voltage at the high voltage bus of PET, and (d) DC link voltage of PET

The simulation results for the three cases show that the proposed optimal coordinated PET and excitation controller is superior to the conventional approach in terms of control performances for the system stability. There are two major reasons for such performances. Firstly, the VSC in the primary and secondary sides of PET can regulate both the magnitude and phase angle of the $\mathrm{AC}$ voltage in rapid response to the requirements of the system, thereby achieving real-time control of the voltage, current and power. Secondly, the energy store unit in the DC link of PET can generate or absorb power even in the transient period, which in turn alleviates the power imbalance in the system, meanwhile the excitation control can also improve the system damping and voltage characteristics in the transient state.

\section{DISCUSSION AND CONCLUSION}

Although we mainly focus on the stability control of PET in this paper, PET with such properties can also meet many new requirements of power systems, for instances:

(1) The ratio of distributed power sources, such as wind turbine generators, photovoltaic systems and low power hydroelectricity systems against the conventional power supply sources, is rising in many power systems due to the environment concerns. Such systems usually have both AC and DC subsystems with different voltages and frequencies. Hence, how to appropriately connect the distributed sources to the existing power system reliably is very important, which can actually be tackled by using PET owing to its variable and flexible frequency and voltage levels on both $\mathrm{AC}$ and $\mathrm{DC}$ subsystems.

(2) For the purpose of supplying reliable, safe and economic energy to consumers, flexible transmission and distribution ( $T$ \& D) systems, such as FACTS, are strongly demanded by current electric power markets, which can actually be realized by PET because it can control power flow in real time and maintain the system stability simultaneously.

(3) A synchronous generator connected with a PET can work in an asynchronous mode in a short period, which can be used to improve the system stability and reliability.
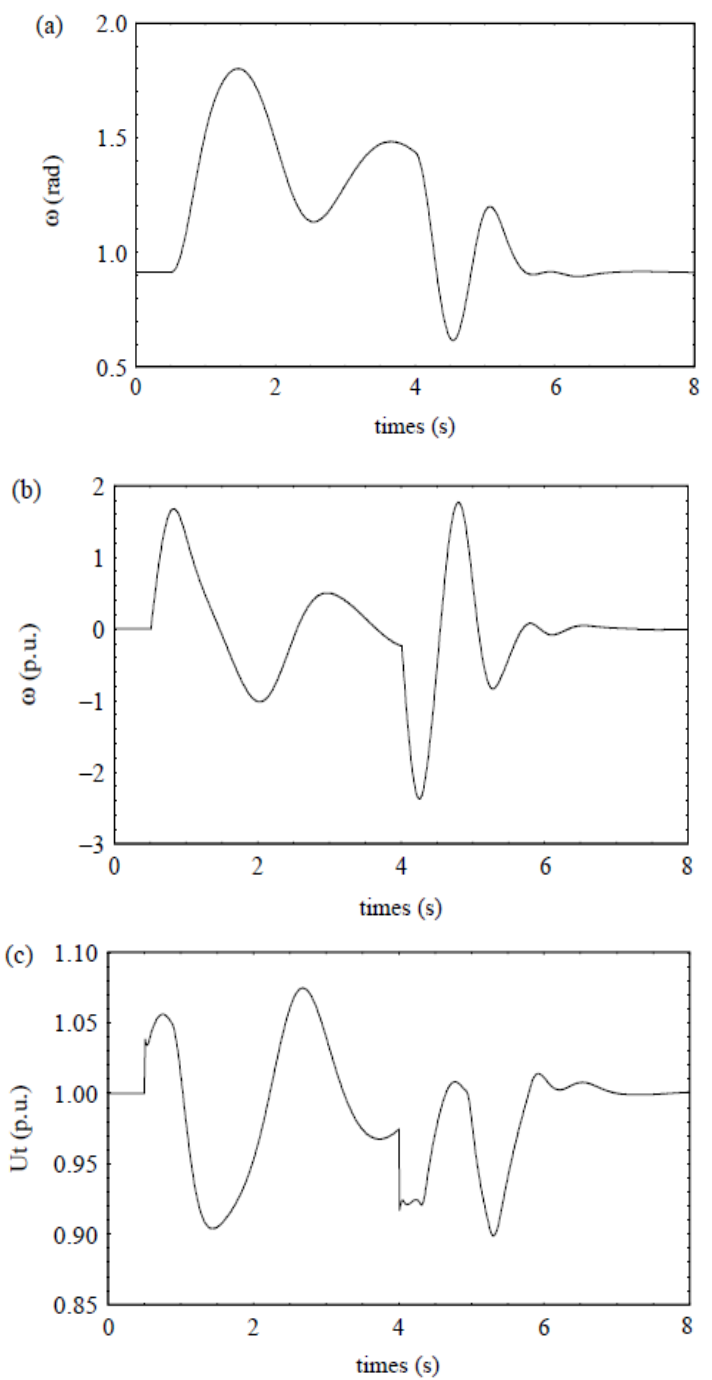

Figure 13. Response to opening and closing of one transmission line for the conventional generator transformer unit: (a) power angle, (b) speed, and (c) voltage at the generator terminals

(4) There is a serious problem nowadays for power quality, such as harmonics, voltage dips, short-term outages and flicker, etc. which can also be alleviated by PET. This paper applied PET to stability control of power systems by deriving a new optimal coordinated PET and generator excitation control strategy. Specifically, we first analysis the coordinated control of generator-PET unit, and then derived a new optimal coordinated PET and generator excitation control. Simulation results show that the proposed controller is superior to the conventional approaches in terms of dynamical performances, and can significantly improve the stability of the system for a variety of disturbances. Compared with the conventional generator-transformer unit, a generator-PET unit can increase the static stability limit and transmission capabilities considerably. Since a generator-PET unit can make the generator always operate under unit power factor, the generator efficiency can also be improved. 
This paper not only provides a feasible control strategy for PET, but also indicates that PET has great potential in the stability control of power systems. As a future topic, we will further examine the effectiveness of PET on multimachine systems from both theoretical and computational viewpoints.
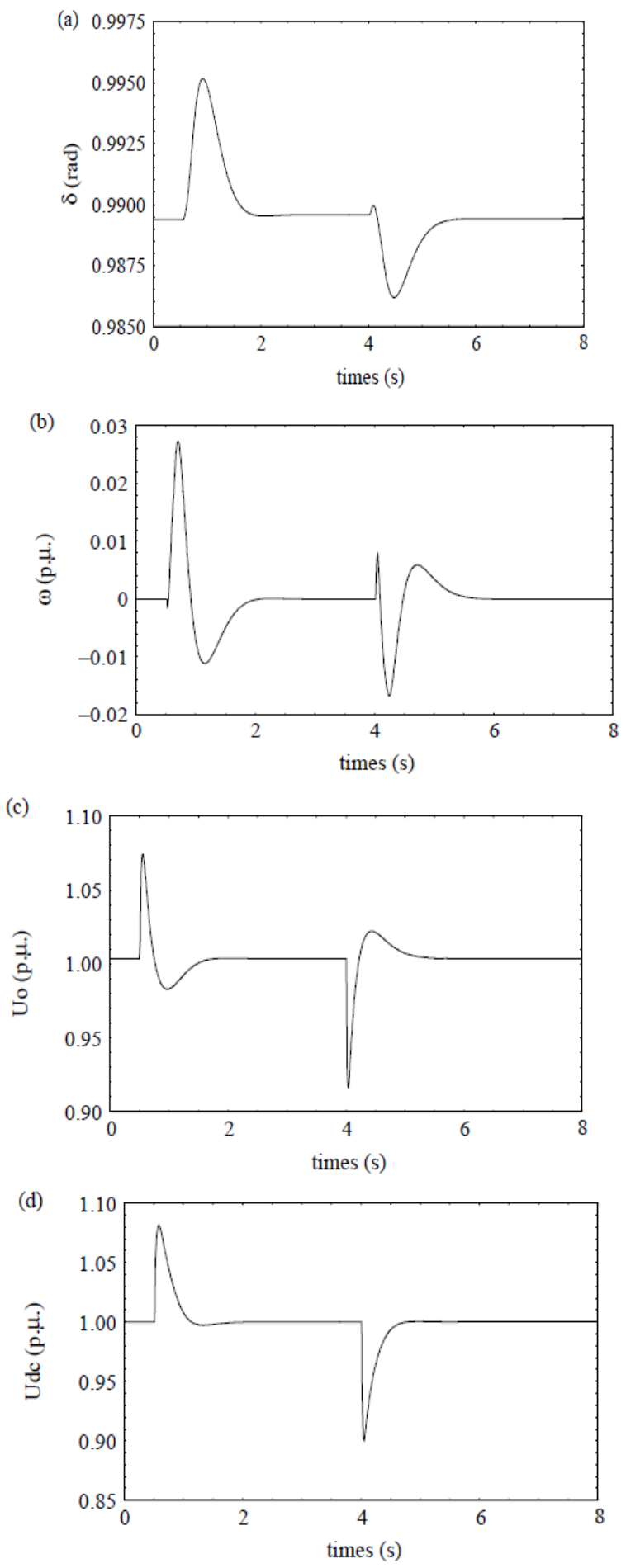

Figure 14. Response to opening and closing of one of the transmission line for the generator-PET unit: (a) power angle, (b) speed, (c) voltage at the high voltage bus of PET, and (d) DC link voltage of PET

Appendix A. Data of single machine infinite bus system

(1) Generator parameters in p.u.:

$$
\begin{aligned}
& X_{d}=0.939, \quad X_{q}=0.690, \quad X_{d}^{\prime}=0.315, \\
& T_{d 0}^{\prime}=10.1 \mathrm{~s}, \quad H=8.922 \mathrm{~s} .
\end{aligned}
$$

(2) Transmission line and transformer parameters in p.u.:

$X_{1}=X_{2}=0.06, \quad X_{\text {Line }}=0.35, \quad X_{\text {tr }}=0.13$.

(3) AVR and conventional PSS:

$$
\begin{aligned}
& E_{f d}=K_{a} \Delta U_{t}+K_{i} \int \Delta U_{t} \mathrm{~d} t \\
& V(s)=-\frac{K_{d}}{K_{a}} \frac{s T_{q}}{1+s T_{q}} \frac{1+s T_{1}}{1+s T_{2}} \omega(s) \\
& K_{a}=200, \quad K_{d}=2.0, \quad K_{i}=1.0, \quad T_{q}=1.5, \\
& T_{1}=2.0, \quad T_{2}=0.2 .
\end{aligned}
$$

\section{RESULTS}

The graphs shown in the subsection below will provide the

\begin{tabular}{|c|c|c|c|c|c|c|c|c|c|}
\hline & \multicolumn{3}{|c|}{$\begin{array}{l}\text { AVR WITHOUT } \\
\text { CONTROLLER }\end{array}$} & \multicolumn{3}{|c|}{$\begin{array}{l}\text { AVR WITH PID } \\
\text { CONTROLLER }\end{array}$} & \multicolumn{3}{|c|}{$\begin{array}{l}\text { AVR WITH FUZZY LOGIC } \\
\text { CONTROLLER }\end{array}$} \\
\hline & $\begin{array}{l}\text { ELECTRIC } \\
\text { AL } \\
\text { TORQUE }\end{array}$ & $\begin{array}{l}\text { LOAD } \\
\text { ANGL } \\
\text { E }\end{array}$ & $\begin{array}{l}\text { TERMINA } \\
\text { L VoLTAG } \\
\text { E }\end{array}$ & $\begin{array}{l}\text { ELECT } \\
\text { RICAL } \\
\text { TORQ } \\
\text { UE }\end{array}$ & $\begin{array}{l}\text { LOAD } \\
\text { ANGL } \\
\text { E }\end{array}$ & $\begin{array}{l}\text { TERMI } \\
\text { NAL } \\
\text { VOLT } \\
\text { AGE }\end{array}$ & $\begin{array}{l}\text { ELECT } \\
\text { RICAL } \\
\text { TORQ } \\
\text { UE }\end{array}$ & $\begin{array}{l}\text { LOAD } \\
\text { ANGL } \\
\text { E }\end{array}$ & $\begin{array}{l}\text { TERMINAL } \\
\text { VOLTAGE }\end{array}$ \\
\hline $\begin{array}{l}\text { Over } \\
\text { Shooot } \\
\text { Time }\end{array}$ & 2.45 & 1.20 & 1.25 & 2.35 & 0.98 & 1.195 & 2.30 & 0.93 & 1.180 \\
\hline $\begin{array}{l}\text { Settling } \\
\text { Time }\end{array}$ & $18 \mathrm{sec}$ & $\begin{array}{l}17.5 \\
\text { sec }\end{array}$ & $16 \mathrm{sec}$ & $17 \mathrm{sec}$ & $16 \mathrm{sec}$ & $14 \mathrm{sec}$ & $16 \mathrm{sec}$ & $\begin{array}{l}15.5 \\
\text { sec }\end{array}$ & $13 \mathrm{sec}$ \\
\hline
\end{tabular}
comparative performance results between the PID controller and the fuzzy logic. Two different situations were analyzed, the AVR with PID controller and the AVR with fuzzy logic controller at a one machine excitation control done with MATLAB Software.

\subsection{PID controller results in a one machine system}

The block diagram shown below for a synchronous machine for which output voltage is controlled by an AVR applied to the excitation system, in the MATLAB simulation. It is very interesting to investigate the effects of each PID controller parameters $\mathrm{Kp}, \mathrm{Ki}$, and $\mathrm{Kd}$ on terminal voltage response that exists on the excitation system only. Tuning the PID controller by setting the proportional gain $\mathrm{Kp}$ to $1, \mathrm{Ki}$ to 0.5 and $\mathrm{Kd}$ to 0.005 then the frequency deviation step response $\Delta \omega$ has similar response. Also the time taken for the terminal voltage to reach the value of 1 p.u is now $0.8 \mathrm{sec}$, it found that these settings of $\mathrm{Kp}, \mathrm{Ki}$, and $\mathrm{Kd}$ don't produce an overall response. From these responses and refer to tuning method, the best values of PID controller parameters for the excitation and governing systems are selected as

$\mathrm{Kp}=1, \mathrm{Ki}=2$ and $\mathrm{Kd}=0.005$

For the governing system the values of $\mathrm{Kp}, \mathrm{Ki}$ and $\mathrm{Kd}$ are set as,

$\mathrm{Kp}=0.8, \mathrm{Ki}=0, \mathrm{Kd}=0.6$

The simulation diagram for the PID controller are as shown below: 


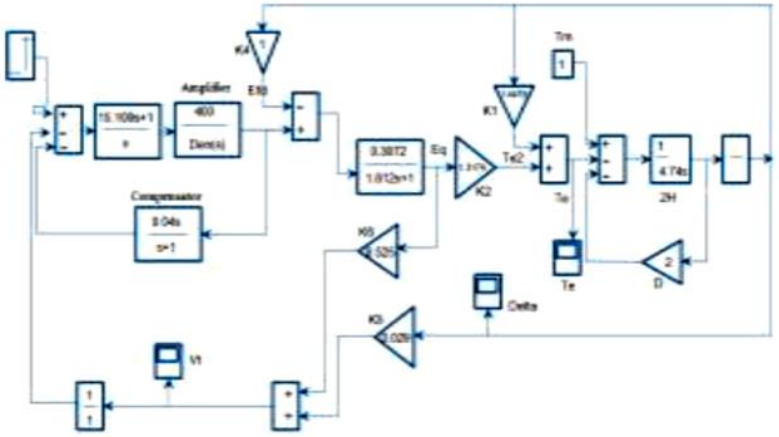

Figure 15. Simulink model of one synchronous machine with AVR using PID controller

\subsection{Fuzzy results in a one machine system}

Fuzzy logic is a derivative from classical Boolean logic and implements a soft linguistic variable on a continuous range of truth values to be defined between conventional binary. Since fuzzy logic handles approximate information in a systematic way, it is a deal for controlling non-linear systems and for modeling complex systems where an inexact model exists. A typical fuzzy system consists of rule base, membership functions and an interference procedure. Fuzzy logic is a superset of conventional Boolean logic that has been extended to handle the concept of truth values between "completely true" and "completely false".

\subsubsection{Fuzzyfication}

It maps from the crisp input space to fuzzy sets in certain input universe of discourse, so for a specific input value it is mapped to the degree of membership.

\subsubsection{Inference mechanism}

It plays an essential role and consists of a set of fuzzy if then rules such as, if $\mathrm{X}$ is $\mathrm{A}, \mathrm{Y}$ is $\mathrm{B}$ and $\mathrm{Z}$ is $\mathrm{C}$, where $\mathrm{r}, \mathrm{y}$ and $\mathrm{z}$ are linguistic variables representing two input variables, and one control output. A, B and $\mathrm{C}$ are linguistic values.

\subsubsection{Knowledge base}

It comprises the definitions of fuzzy membership functions for the input and output variables and the necessary control rules which specify the control action by using the linguistic terms.

\subsubsection{Defuzzyfication}

It converts the linguistic variables deterministic numerical values. The various defuzzification methods are,

Centroid Average (CA)

Maximum Center Average (MCA)

Mean Of Maximum (MOM)

Smallest Of Maximum (SOM)

Largest Of Maximum (LOM)

\section{CONCLUSION}

It is observed for both the studies (MATLAB simulation and stability program simulation) an excellent response of the PID controller and fuzzy logic controller and with no oscillations, while the AVR response presented a ripple in both studies and some oscillations before reaching the steady state operation point. It is shown that an excellent performance of the PID controller and fuzzy logic controller over the conventional one for the excitation control of synchronous machines could be achieved.

This paper has demonstrated the implementation of a FLC for the control of fluctuated AC line to a consumer home. The PID - FLC is easy to implement and require a small amount of in expensive components in compact size. The controller showed good ratification performance between $150 \mathrm{~V}$ and $250 \mathrm{~V}$ input and provide a stable output. The test result shown that the output transient voltage last only 2 seconds and a stable output are established.

This paper develops two advanced control methods applied on the automatic voltage regulation of turbo-alternators: an adaptive hybrid learning stabilizer based ANFIS and a standard fuzzy controller, to improve static and dynamic stability of a Standard - IEEE power system type SMIB. This concept allows accurately and reliably carrying out transient stability study of power system and its controllers for voltage and speeding stability analyses. It considerably increases the power transfer level via the improvement of the transient stability limit. The computer simulation results have proved the efficiency and robustness of the learning NFC, in comparison using simple fuzzy and the test conventional PID stabilizers, showing stable system responses almost insensitive under different modes of the station. This learning control possesses the capability to improve its performance over time by interaction with its environment.

\section{REFERENCES}

[1] Clerc M, Kennedy J. (2002). The particle swarm explosion, stability and convergence in a multidimentional complex space. IEEE Transactions on Evolutionary Computation 6(1): 58-73. https://doi.org/10.1109/4235.985692

[2] Gaing ZL. (2004). A particle swarm optimization approach for optimum design of PID controller in AVR system. IEEE Transactions on Energy Conversion 19(2): 384-391. https://doi.org/10.1109/TEC.2003.821821

[3] Anderson PM, Fouad AA. (1995). Power system control and stability. IEEE https://doi.org/10.1109/TSMC.1979.4310158

[4] Hadi S. (1999). Power System Analysis. Tata McGrawHill.

[5] Mamdani EH. (1975). An experiment in linguistic synthesis with a fuzzy logic controller. International Journal of Human-Computer Studies 51(1): 1-13. https://doi.org/10.1016/S0020-7373(75)80002-2

[6] Lee CC. (1990). Fuzzy logic in control systems. IEEE Transactions on Systems, Man and Cybernetics 20(2). https://doi.org/10.1109/21.52551

[7] Zadeh LA. (1965). Fuzzy Sets. Informat and Control 8(3): 338-353. 9958(65)90241-X

[8] Chalmers BJ. (1992). Influence of saturation in brushless permanent-magnet motor drives. Electric Power Applications, IEE Proceedings B [see also IEE Proceedings-Electric Power Applications] 139(1): 51-52. https://doi.org/10.1049/ip-b.1992.0007

[9] Johnson CT. (1992). Experimental identification of friction and its compensation in precise, position controlled mechanisms. IEEE Transactions on Industry 
Applications

28(6):

$1392-1398$

https://doi.org/10.1109/28.175293

[10] Canudas C, Astrom KJ, Braun K. (1987). Adaptive friction compensation in DC-motor drives. IEEE Journal on Robotics and Automation RA-3(6): 1556-1561. https://doi.org/10.1109/ROBOT.1986.1087407

[11] Wishart MT, Harley RG. (1995). Identification and control of induction machines using artificial neural networks. IEEE Transactions on Industry Applications 31(3): 612-619. https://doi.org/10.1109/28.382123

[12] Kung YS, Liaw CM, Ouyang MS. (1995). Adaptive speed control for induction motor drives using neural networks. Industrial Electronics, Control, and Instrumentation 42(1): 25-32. https://doi.org/10.1109/IECON.1993.339083

[13] Kundur P. (1994). Power System Stability and Control. McGraw-Hill.

[14] Kundur P, Klein M, Rogers GJ, Zywno MS. (1989). Application of pss for enhancement of overall system stability. IEEE Power Engineering Review 9(5): 614-626. https://doi.org/10.1109/MPER.1989.4310703

[15] Toliyat HA, Sadeh J, Ghazi R. (1996). Design of augmented fuzzy logic power system stabilizers to enhance power systems stability. IEEE Transactions on Energy Conversion 11(1): 97-103. https://doi.org/10.1109/60.486582

[16] Anderson PM, Fouad AA. (1977). Power system control and stability. The Iowa State University Press. https://doi.org/10.1109/TSMC.1979.4310158

[17] Lee CC. (1990). Fuzzy logic in control systems. IEEE Transactions on Systems, Man, and Cybernetics 20(2). https://doi.org/10.1109/21.52551
[18] Jang JR, Sun C, Mijutani E. (2004). Neuro-Fuzzy and Soft Computing. Pearson Education.

[19] Yadiah N, Ganga Dinesh Kumar A, Bhattacharya JL. (2004). Fuzzy based coordinated controller for power system stability and voltage regulation. Electric Power Systems Research 69(2): 169-177. https://doi.org/10.1016/j.epsr.2003.08.008

[20] Nallathambi N, Neelakantan PN. (2004). Fuzzy logic based power system stabilizer. E-Tech 2004: 68-73. https://doi.org/10.1109/ETECH.2004.1353846

[21] Naceri A. (2002). Application of the advanced robust H2 and $\mathrm{H}_{\infty}$ frequency control techniques on the AVR- PSS for SM. Ph.D. Dissertation, Dept. of Electrical Eng.

[22] Manoj J, Qureshi MF, Srivastav P. (2013). Design of adaptive grey fuzzy pid controller with variable prediction step-size for power system dynamic stability control and its on-line rule tuning. AMSE Journals, Series Advances C, (Automatic Control, Theory and Application) 68(1): 1-21.

[23] Manoj J, Qureshi MF, Srivastav P. (2013). Designing power system stabilizer for system damping for transient disturbances using grey ANFIS technique. AMSE Journals, Series Advances C (Automatic Control: Theory and Application) 68(2): 36-53.

[24] Dewangan DN, Manoj J, Qureshi MF, Banjare YP. (2012). Real-time fault diagnostic and rectification system for bearing vibration of steam turbine by using adaptive neuro-fuzzy inference system and genetic algorithm-a novel approach. AMSE Journals, Series Advances B (Signal Processing and Pattern Recognition) 55(1): 1-21. 